\title{
Pollution \\ Control \\ Device
}

In the accompanying photo, the unit at left is a PrecipTech Power Guard SQ-200 Automatic Voltage Controller which, combined with a remote computer, represents an automatic management system for smoke-cleaning precipitators employed for air pollution control by smokestack industries. The Power Guard SQ200 is an offshoot of an original SQ-100 developed in a research program conducted by Langley Research Center. The latter system was jointly designed and developed by Kinetic Controls, Inc., Newport News, Virginia and PrecipTech Inc., ESP Specialties, Kansas City, Missouri; PrecipTech now markets the control.

An electrostatic precipitator cleans smoke by removing particulate matter from smokestackgases before the gases are expelled into the atmosphere. Smokestack gas is passed through a precipitator chamber and exposed to an electrostatic field; dust particles in the gas become electrically charged and migrate to collection surfaces where they are "captured." For maximum particle collection, the precipitator must be operated at the highest possible electrical field strength.

Sparking, a normal function of electrostatic precipitation, can limit collection efficiency if not controlled. The Power Guard SQ200 automatically monitors sparking and quenches sparks before arcing develops; it also automatically adjusts to changes in operating conditions. The unit's ability to fine-tune itself after initial set-up virtually eliminates the need for monitoring by highly skilled operators. It has demonstrated reliability on precipitators in cement plants, paper mills, steel mills, utilities and refuse incinerators.

The initial precipitator control was invented in the course of a 1980 program seeking a way to dispose of refuse in areas where acceptable landfill sites are scarce. Langley Research Center, Langley Air Force Base and the adjoining

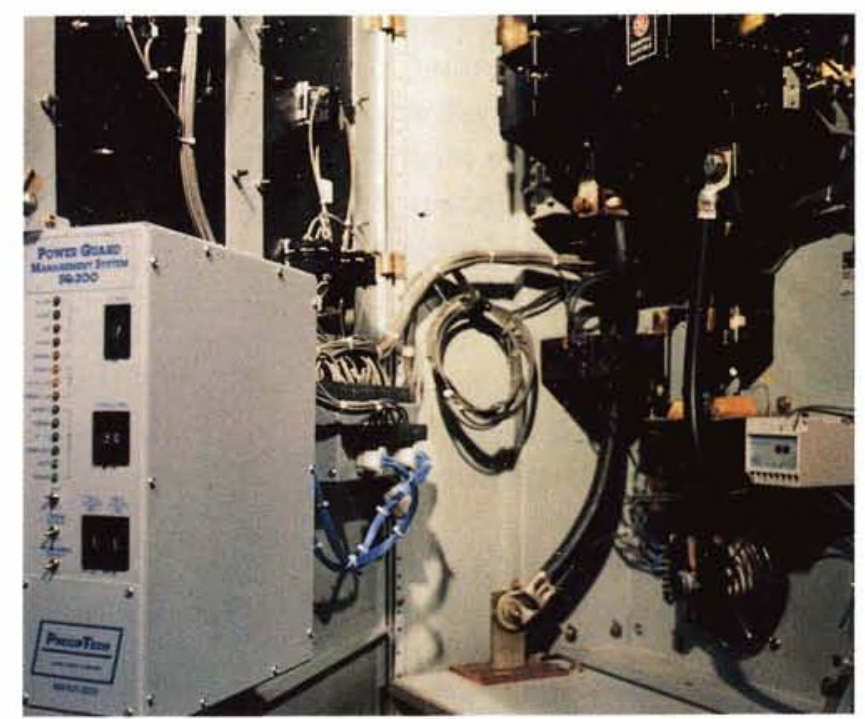

City of Hampton, Virginia teamed in a highly successful effort to develop a Refuse-fired Steam Generating Facility that incinerates trash, reduces it to a readily disposable ash, and recovers the heat of trash-burning to create steam for practical use at Langley Research Center.

The control evolved as an answer to a problem of excessive stack emissions. When refuse is used as a fuel, the chemical composition of the exhaust gas in the smokestack changes continually - and that requires a voltage controller capable of following process changes. It was necessary, therefore, to develop a control system that matched voltage to smoke changes to insure minimal air pollution.

Two NASA employees - David F. Johnston and T.K. Lusby, Jr. - undertook to develop the control, working for the most part on personal time and with private funds. They successfully produced an innovative, microprocessor based control that automatically senses and compensates for process changes by adjusting precipitator voltage and current for maximum particle collection. In 1987, Johnston formed Kinetic Controls to commercialize the invention. 